\title{
Provisional Life Expectancy Estimates for January through June, 2020
}

\author{
Elizabeth Arias, Ph.D., Betzaida Tejada-Vera, M.S., and Farida Ahmad, M.P.H.
}

\section{Introduction}

The National Center for Health Statistics (NCHS) collects and disseminates the nation's official vital statistics through the National Vital Statistics System (NVSS). NCHS uses provisional vital statistics data for conducting public health surveillance and final data for producing annual national natality and mortality statistics. NCHS publishes annual and decennial national life tables based on final vital statistics. In order to assess the effects on life expectancy of excess mortality observed during 2020, NCHS is publishing, for the first time, life tables based on provisional vital statistics data. Provisional data are early estimates based on death certificates received, processed, and coded but not finalized by NCHS. These estimates are considered provisional because death certificate information may later be revised and additional death certificates may be received until approximately 6 months after the end of the data year.

This report presents life expectancy estimates based on provisional death counts for the months January through June, 2020, by sex, for the total, Hispanic, non-Hispanic white, and nonHispanic black populations. Abridged period life tables calculated to produce the provisional life expectancy estimates are also provided via Internet tables (see Technical Notes and Internet tables 1-15). Life expectancy estimates based on final data for 2019 by sex, Hispanic origin, and race are also provided in this report for purposes of comparison (see Technical Notes and reference 1 for description of methodology).
Keywords: life expectancy • Hispanic origin $\bullet$ race $\bullet$ National Vital Statistics System

\section{Data and Methods}

Provisional life expectancy estimates were calculated using abridged period life tables based on provisional death counts for the first half of 2020 from death records received and processed by NCHS as of October 26, 2020; provisional numbers of births for the same period based on birth records received and processed by NCHS as of October 27, 2020; and, April 1, 2020 monthly postcensal population estimates based on the 2010 decennial census. Provisional mortality rates are typically computed using death data after a 3-month lag following date of death, as completeness and timeliness of provisional death data can vary by many factors, including cause of death, month of the year, and age of the decedent $(2,3)$. Mortality data used in this report include over $99 \%$ of the deaths that occurred from January through June, 2020, but certain jurisdictions and age groups may be underrepresented for the latter months in the period (3). Deaths requiring investigation, including infant deaths, deaths from external injuries, and drug overdose deaths may be underestimated $(4,5)$. See Technical Notes for more information about the calculation of the abridged period life tables and 2019 life expectancy estimates by race and Hispanic origin.

\section{Results}

\section{Life expectancy in the United States}

The Table summarizes life expectancy by age, Hispanic origin, race, and sex. Life expectancy at birth represents the average number of years that a group of infants would live if they were to experience throughout life the agespecific death rates prevailing during a specified period. In the first half of 2020, life expectancy at birth for the total U.S. population was 77.8 years, declining by 1.0 year from 78.8 in 2019 (6). Life expectancy at birth for males was 75.1 years in the first half of 2020, representing a decline of 1.2 years from 76.3 years in 2019. For females, life expectancy declined to 80.5 years, decreasing 0.9 year from 81.4 years in 2019 (Figure 1).

The difference in life expectancy between the sexes was 5.4 years in the first half of 2020, increasing from 5.1 in 2019. Between 2000 and 2010, the difference in life expectancy between the sexes narrowed from 5.2 years to its lowest level of 4.8 years and then gradually increasing to 5.1 years in 2019 (Figure 1).

\section{Life expectancy by Hispanic origin and race}

Between 2019 and the first half of 2020, life expectancy decreased 2.7 years for the non-Hispanic black population (74.7 to 72.0) (Figure 2). It decreased by 1.9 years for the Hispanic population (81.8 to 79.9 ) and by 0.8 year for the non-Hispanic white population 
Table. Expectation of life by age, Hispanic origin, race for the non-Hispanic population, and sex: United States, 2020

\begin{tabular}{|c|c|c|c|c|c|c|c|c|c|c|c|c|}
\hline \multirow[b]{2}{*}{ Age (years) } & \multicolumn{3}{|c|}{ All origins } & \multicolumn{3}{|c|}{ Hispanic $^{1}$} & \multicolumn{3}{|c|}{ Non-Hispanic white ${ }^{1}$} & \multicolumn{3}{|c|}{ Non-Hispanic black ${ }^{1}$} \\
\hline & Total & Male & Female & Total & Male & Female & Total & Male & Female & Total & Male & Female \\
\hline 0 & 77.8 & 75.1 & 80.5 & 79.9 & 76.6 & 83.3 & 78.0 & 75.5 & 80.6 & 72.0 & 68.3 & 75.8 \\
\hline 1 & 77.2 & 74.5 & 80.0 & 79.3 & 76.0 & 82.7 & 77.4 & 74.9 & 79.9 & 71.8 & 68.1 & 75.5 \\
\hline 5 & 73.3 & 70.6 & 76.0 & 75.4 & 72.1 & 78.8 & 73.4 & 71.0 & 75.9 & 67.9 & 64.2 & 71.6 \\
\hline 10 & 68.3 & 65.6 & 71.0 & 70.4 & 67.1 & 73.8 & 68.4 & 66.0 & 71.0 & 63.0 & 59.3 & 66.7 \\
\hline 15 & 63.4 & 60.7 & 66.1 & 65.4 & 62.1 & 68.8 & 63.5 & 61.1 & 66.0 & 58.1 & 54.4 & 61.7 \\
\hline 20 & 58.5 & 55.9 & 61.2 & 60.6 & 57.3 & 63.9 & 58.6 & 56.3 & 61.1 & 53.4 & 49.8 & 56.9 \\
\hline 25 & 53.8 & 51.3 & 56.3 & 55.8 & 52.7 & 59.1 & 53.9 & 51.6 & 56.3 & 48.9 & 45.5 & 52.1 \\
\hline 30 & 49.2 & 46.8 & 51.5 & 51.1 & 48.1 & 54.2 & 49.2 & 47.0 & 51.5 & 44.4 & 41.1 & 47.4 \\
\hline 35 & 44.6 & 42.3 & 46.8 & 46.5 & 43.5 & 49.4 & 44.6 & 42.6 & 46.7 & 39.9 & 36.8 & 42.8 \\
\hline 40 & 40.0 & 37.8 & 42.1 & 41.8 & 39.0 & 44.6 & 40.1 & 38.1 & 42.1 & 35.5 & 32.6 & 38.3 \\
\hline 45 & 35.5 & 33.4 & 37.5 & 37.3 & 34.6 & 39.9 & 35.6 & 33.7 & 37.4 & 31.3 & 28.5 & 33.9 \\
\hline 50 & 31.1 & 29.2 & 33.0 & 32.8 & 30.2 & 35.2 & 31.2 & 29.4 & 32.9 & 27.2 & 24.6 & 29.6 \\
\hline 55 & 26.9 & 25.1 & 28.6 & 28.5 & 26.1 & 30.7 & 26.9 & 25.3 & 28.5 & 23.3 & 20.8 & 25.5 \\
\hline 60 & 22.9 & 21.3 & 24.4 & 24.4 & 22.2 & 26.4 & 22.9 & 21.5 & 24.3 & 19.7 & 17.5 & 21.7 \\
\hline 65 & 19.1 & 17.8 & 20.4 & 20.6 & 18.7 & 22.3 & 19.1 & 17.9 & 20.2 & 16.5 & 14.5 & 18.1 \\
\hline 70 & 15.5 & 14.4 & 16.5 & 17.0 & 15.4 & 18.3 & 15.4 & 14.4 & 16.3 & 13.6 & 11.9 & 14.8 \\
\hline 75 & 12.2 & 11.3 & 12.9 & 13.7 & 12.4 & 14.6 & 12.0 & 11.2 & 12.7 & 10.8 & 9.6 & 11.8 \\
\hline 80 & 9.3 & 8.6 & 9.7 & 10.7 & 9.8 & 11.4 & 9.0 & 8.4 & 9.5 & 8.5 & 7.5 & 9.1 \\
\hline 85 & 6.8 & 6.4 & 7.0 & 8.3 & 7.7 & 8.8 & 6.5 & 6.1 & 6.7 & 6.5 & 5.9 & 6.8 \\
\hline
\end{tabular}

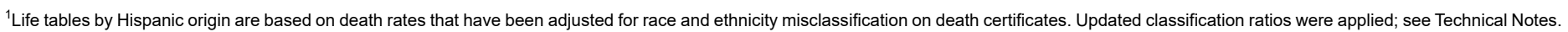
NOTES: Estimates are based on provisional data from January 2020 through June 2020. Provisional data are subject to change as additional data are received.

SOURCE: National Center for Health Statistics, National Vital Statistics System, Mortality, 2020.

Figure 1. Life expectancy at birth, by sex: United States, 2000-2020

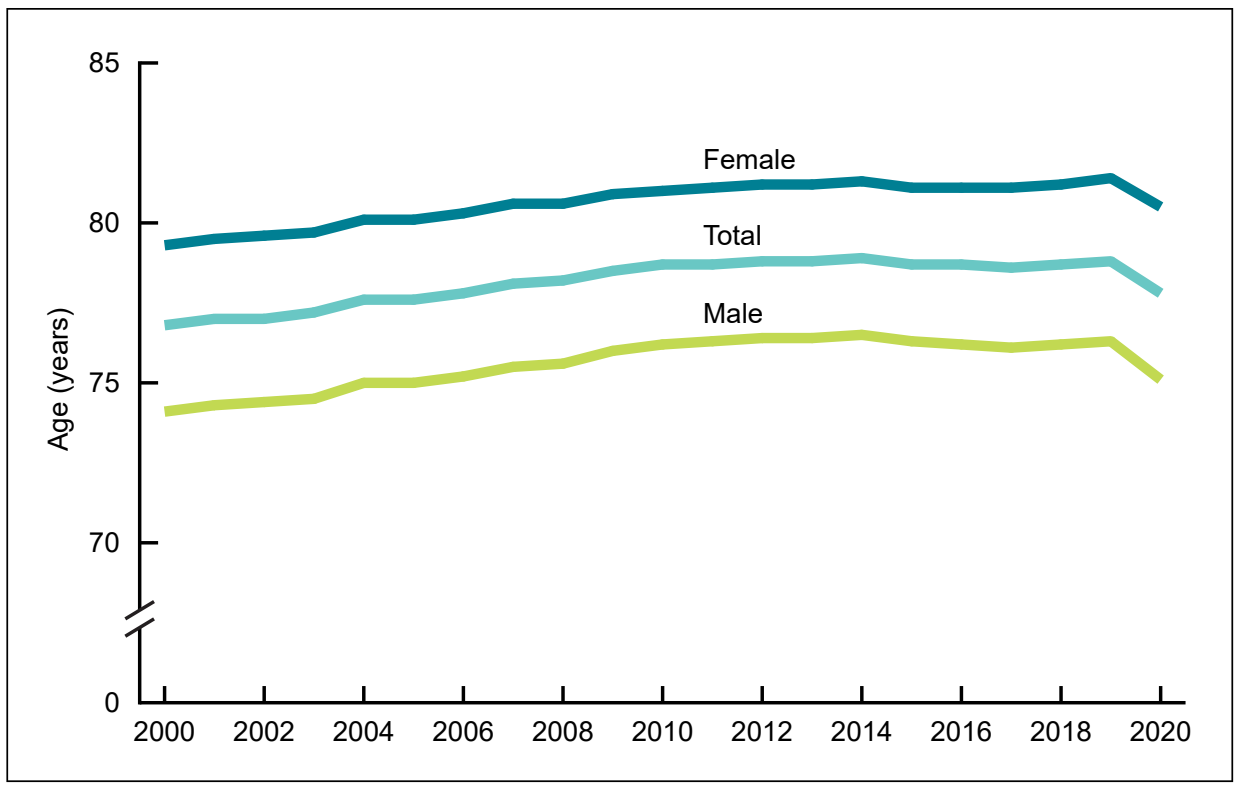

NOTES: Life expectancies for 2019 by Hispanic origin and race are not final estimates; see Technical Notes. Estimates are based on provisional data from January 2020 through June 2020.

SOURCE: National Center for Health Statistics, National Vital Statistics System, Mortality data.

(78.8 to 78.0). In the first half of 2020 , the Hispanic population had a life expectancy advantage of 1.9 years over the non-Hispanic white population, declining from an advantage of 3.0 years in 2019 (Figure 3). The Hispanic advantage relative to the non-Hispanic black population increased from 7.1 to
Among the six Hispanic origin and race-sex groups (Figure 4), the decrease in life expectancy between 2019 and the first half of 2020 was highest for non-Hispanic black males whose life expectancy declined by 3.0 years $(71.3$ to 68.3), followed in order by Hispanic males with a decline of 2.4 years $(79.0$ to 76.6), non-Hispanic black females with a decline of 2.3 years (78.1 to 75.8 ), Hispanic females with a decline of 1.1 years (84.4 to 83.3), non-Hispanic white males with a decline of 0.8 year (76.3 to 75.5), and non-Hispanic white females with a decline of 0.7 year (81.3 to 80.6).

\section{Discussion and Conclusions}

Provisional life expectancy at birth in the first half of 2020 was the lowest level since 2006 for both the total population (77.8 years) and for males (75.1), and was the lowest level since 2007 for females (80.5). Life expectancy for the nonHispanic black population, 72.0, declined the most, and was the lowest estimate seen since 2001 (for the black population regardless of Hispanic origin). The Hispanic population experienced the 
Figure 2. Life expectancy at birth, by Hispanic origin and race: United States, 2019 and 2020

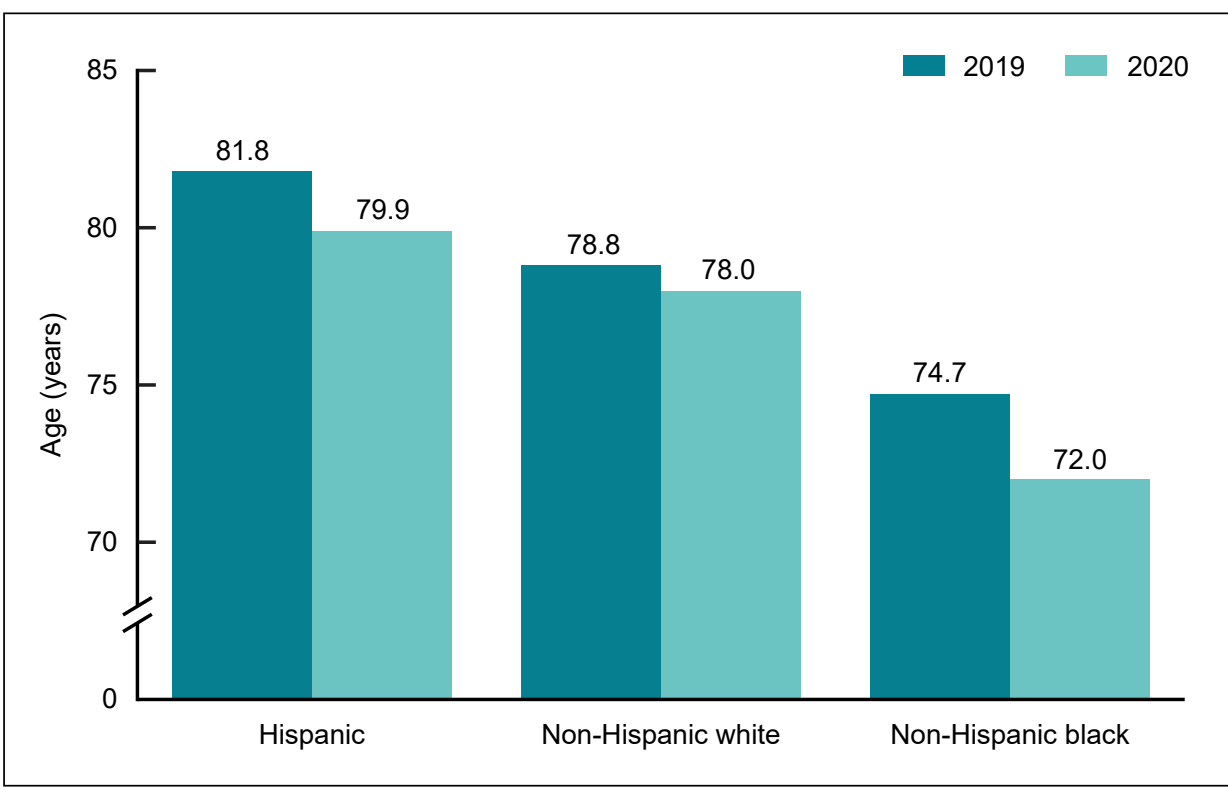

NOTES: Life expectancies for 2019 by Hispanic origin and race are not final estimates; see Technical Notes. Estimates are based on provisional data from January 2020 through June 2020.

SOURCE: National Center for Health Statistics, National Vital Statistics System, Mortality data.

Figure 3. Differences between groups in life expectancy at birth: United States, 2019 and 2020

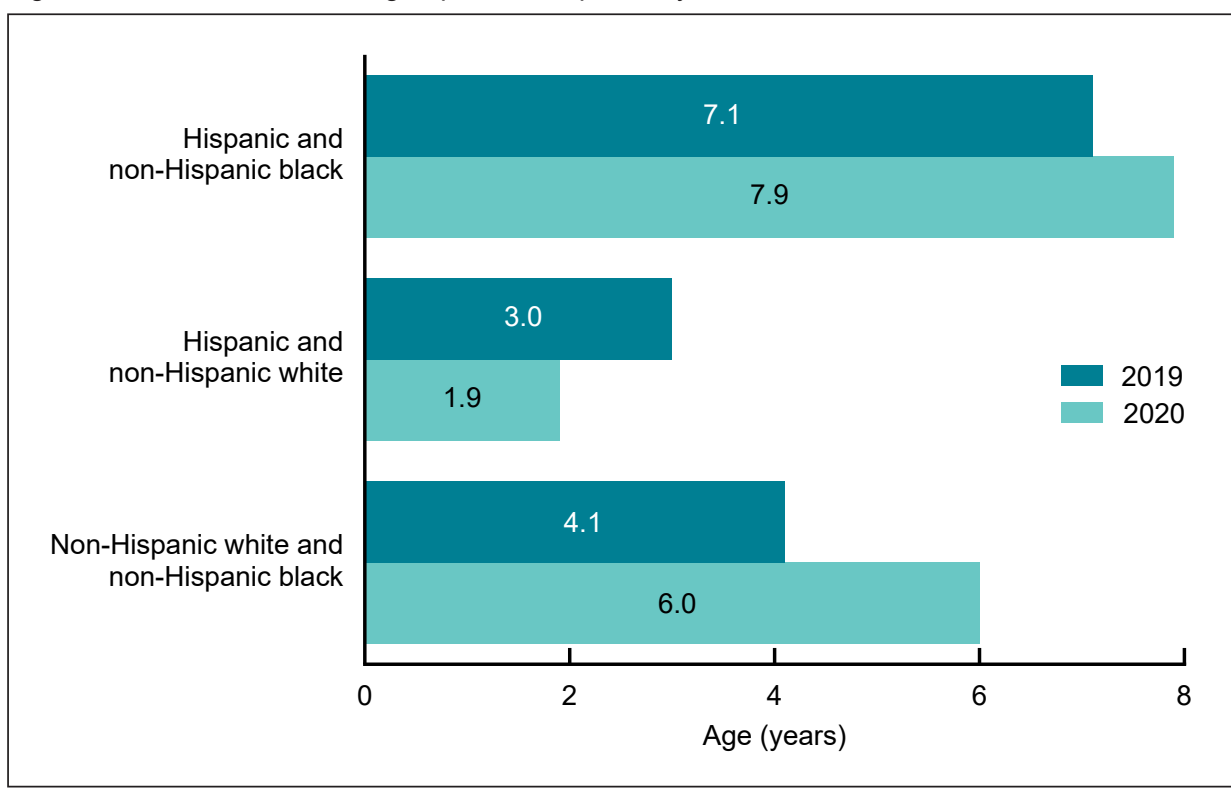

NOTES: Life expectancies for 2019 by Hispanic origin and race are not final estimates; see Technical Notes. Estimates are based on provisional data from January 2020 through June 2020

SOURCE: National Center for Health Statistics, National Vital Statistics System, Mortality data.

second largest decline in life expectancy (79.9) reaching a level lower than what it was in 2006, the first year for which life expectancy estimates by Hispanic origin were produced (80.3). The levels observed for the non-Hispanic white population were last seen in 2005 for the white population (regardless of Hispanic origin) (7).
Another consequence of the decreased life expectancy estimates observed during the first half of 2020 was a worsening of racial and ethnic mortality disparities. For example, the gap in life expectancy at birth between the nonHispanic black and white populations increased by $46 \%$ between 2019 and the first half of 2020 (from 4.1 to 6.0 years).
Regardless of Hispanic origin, life expectancy for the black population has consistently been lower than that of the white population but the gap between the two races had generally been narrowing since 1993 when it was 7.1 (7). The gap of 6.0 observed in the first half of 2020 is the largest since 1998 (7).

Conversely, the gap between the Hispanic and non-Hispanic white populations decreased by $37 \%$ between 2019 and the first half of 2020 (from 3.0 to 1.9 years). This indicates that the Hispanic population lost some of the mortality advantage it has evidenced since 2006 relative to the non-Hispanic white population, despite experiencing generally lower socioeconomic status $(8-10)$.

The provisional life expectancy estimates presented in this report are subject to important limitations. First, they are based on deaths that occurred during the first 6 months of the year and do not reflect the entirety of the effects of the COVID-19 pandemic in 2020, or other changes in causes of death, such as the increases in provisional drug overdose deaths through early 2020 (11). There is seasonality in death patterns in any given year, with winter months typically seeing more deaths than summer months, and this is not accounted for in the data. Second, the COVID-19 pandemic differentially affected certain geographic areas in the first half of 2020. The life table estimates may disproportionately represent mortality in those regions, which are more urban and have different demographic characteristics than areas affected by the pandemic in the latter part of the year. As a result, life expectancy at birth for the first half of 2020 may be underestimated since the populations more severely affected, Hispanic and non-Hispanic black populations, are more likely to live in urban areas.

The provisional mortality data on which the life tables are based also have a number of limitations. First, the timeliness of death certificate data varies by jurisdiction. Some jurisdictions 
Figure 4. Change in life expectancy at birth, by Hispanic origin and race and sex: United States, 2019 and 2020

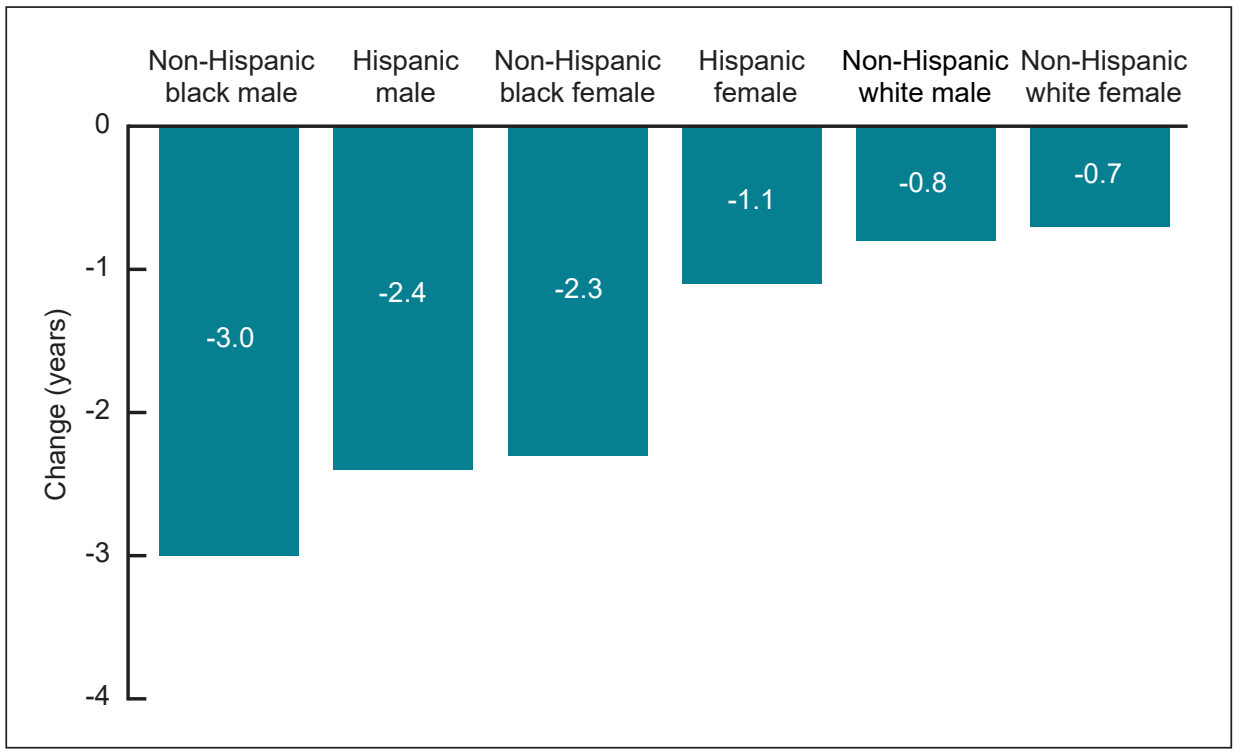

NOTES: Life expectancies for 2019 by Hispanic origin and race are not final estimates; see Technical Notes. Estimates are based on provisional data from January 2020 through June 2020.

SOURCE: National Center for Health Statistics, National Vital Statistics System, Mortality data.

have historically taken longer to submit death certificates because of paper records, staffing shortages, or other localized issues. More recently, jurisdictions were differently affected by the pandemic. Many jurisdictions increased their frequency of death certificate submissions, while some faced staffing challenges, data processing disruptions, or other issues. Some jurisdictions expanded their use of electronic death registration systems in 2020, which may have affected the timeliness of data submission. The effect of recent changes in timeliness will not be apparent until data are finalized. Another limitation is the variation in timeliness due to age and cause of death. Certain age groups, particularly under 5 years, may be underrepresented (3). Completion of death certificates takes longer for deaths from causes requiring investigation, including infant deaths, external injuries, and drug overdose deaths. As a result, these deaths may be underreported in the three to six months after the death occurred. Lastly, the timeliness of death certificate data by race or ethnicity has not been studied. Differences in timeliness by these factors may result in underestimation of deaths for specific groups. The underestimation of infant deaths, for example, will have a disproportionate effect on life expectancy at birth given that infant mortality has a large effect on life expectancy at birth due to it generally being higher than mortality at all other ages up to the mid-50s or so.

\section{References}

1. Arias E, Xu JQ. United States life tables, 2018. National Vital Statistics Reports; vol 69, no 12. Hyattsville, MD: National Center for Health Statistics. 2020. Available from: https://www.cdc.gov/nchs/data/nvsr/ nvsr69/nvsr69-12-508.pdf.

2. Ahmad FB, Bastian B. Quarterly provisional estimates for selected indicators of mortality, 2018Quarter 2, 2020. National Center for Health Statistics. National Vital Statistics System, Vital Statistics Rapid Release Program. 2020. Available from: https://www.cdc. gov/nchs/nvss/vsrr/mortality.htm.

3. Ahmad FB, Dokpesi P, Escobedo L, Rossen L. Timeliness of death certificate data by sex, age, and geography. Vital Statistics Rapid Release; no 9. Hyattsville, MD: National Center for Health Statistics.
June 2020. Available from: https://www.cdc.gov/nchs/data/vsrr/ vsrr009-508.pdf.

4. Rossen LM, Ahmad FB, Spencer MR, Warner M, Sutton P. Methods to adjust provisional counts of drug overdose deaths for underreporting. Vital Statistics Rapid Release; no 6. Hyattsville, MD: National Center for Health Statistics. 2018. Available from: https://www.cdc.gov/nchs/ data/vsrr/report006.pdf.

5. Rossen LM, Womack LS, Spencer MR, Ahmad FB. Timeliness of infant death data for infant mortality surveillance and quarterly provisional estimates. Vital Statistics Rapid Release; no 5. Hyattsville, MD: National Center for Health Statistics. 2018. Available from: https://www.cdc.gov/nchs/data/vsrr/ report005.pdf.

6. Kochanek K, Xu JQ, Arias E. Mortality in the United States, 2019. Data Brief, no 395. Hyattsville, MD: National Center for Health Statistics. 2020. Available from: https:// www.cdc.gov/nchs/data/databriefs/ db395-H.pdf.

7. Arias E, Xu JQ. United States life tables, 2017. National Vital Statistics Reports; vol 68, no 7. Hyattsville, MD: National Center for Health Statistics. 2019. Available from: https://www.cdc.gov/nchs/data/nvsr/ nvsr68/nvsr68_07-508.pdf.

8. Arias E, Heron M, Hakes JK. The validity of race and Hispanic-origin reporting on death certificates in the United States: An update. National Center for Health Statistics. Vital Health Stat 2(172). 2016. Available from: http://www.cdc.gov/nchs/data/ series/sr_02/sr02_172.pdf.

9. Arias E. United States life tables by Hispanic origin. National Center for Health Statistics. Vital Health Stat 2(152). 2010. Available from: http:// www.cdc.gov/nchs/data/series/sr_02/ sr02_152.pdf. 
10. Markides KS, Coreil J. The health of Hispanics in the southwestern United States: An epidemiologic paradox. Public Health Rep 101(3):253-65. 1986.

11. Ahmad FB, Rossen LM, Sutton P. Provisional drug overdose death counts. National Center for Health Statistics. 2020. Available from: https://www.cdc.gov/nchs/nvss/vsrr/ drug-overdose-data.htm.

12. Chiang CL. The life table and its applications. Malabar, FL: R.E. Krieger Publishing Company. 1984.

13. Silcocks PBS, Jenner DA, Reza R. Life expectancy as a summary of mortality in a population: Statistical considerations and suitability for use by health authorities. J Epidemiol Community Health 55:38-43. 2001. 


\section{Technical Notes}

The methodology used to estimate the provisional 2020 life tables (Internet tables 1-12) on which the life expectancy estimates presented in this report are based differs from what is used to estimate the annual U.S. national life tables in several ways (1). First, the life tables presented in this report are based on provisional death counts for half a year rather than on final death counts for a full year. Second, they are based on monthly population estimates rather than annual mid-year population estimates. Third, they are abridged period life tables closed at ages 85 and over rather than complete period life tables closed at ages 100 and over. The main reason for the differences in methodology is data availability. Final death counts for the year 2020 will be not be available until late 2021. Similarly, census mid-year population estimates for 2020 are not yet available. The tables are closed at ages 85 and over because Medicare data, used to supplement vital statistics data at older ages, will not be available until mid2021. Another difference is the use of provisional birth counts for the first half of 2020 rather than final birth counts and linked birth/infant death data used for life tables by Hispanic origin and race as these data are not yet available. Finally, abridged rather than complete life tables were used to address the effects of small death counts for some Hispanic originrace-sex-age groups (Internet tables 1-12).

Standard errors of the two most important functions, the probability of dying and life expectancy (Internet tables 13-14), are estimated under the assumption that the data are only affected by random error because over $99 \%$ of deaths that occurred during the first half of 2020 are included. However, the possibility that certain jurisdictions and age groups may be underrepresented for later months in the period could potentially lead to biases not accounted for by the estimated standard errors. Other possible errors, including age, and Hispanic origin and race misreporting on death certificates are also not considered in the calculation of the variances or standard errors of the life table functions.

Life expectancy estimates presented in this report for 2019 are based on 2019 complete period life tables generated using the same methodology as that used each year to estimate annual U.S. life tables, with a minor modification (1). The standard 2018 and 2019 birth and 2019 mortality data files were used rather than the 2019 linked birth/infant death data file because the latter is not yet available. The final 2019 life tables by Hispanic origin and race will be updated once the linked birth/infant death data are available (Internet table 15).

\section{Data for calculating life table functions}

\section{Vital statistics data}

Mortality data used to estimate the life tables presented in this report include over $99 \%$ of the deaths that occurred from January through June, 2020, although certain jurisdictions and age groups may be underrepresented for later months in the period. Death data are typically over $99 \%$ complete 3 months after the date of death, but this can vary by jurisdiction, age of the decedent, and the cause of death. Most jurisdictions submit over $90 \%$ of death data by 3 months after the date of death, but some jurisdictions may take longer to submit death records. Death data for decedents under age 5 years are $90 \%$ complete 3 months after the date of death, and 95\% complete by 6 months after the death occurred. Infant death records often take longer to complete because infant deaths often require additional investigation. As a result, provisional estimates of infant mortality are typically presented with a nine-month lag after death. Timeliness also varies by cause of death, with deaths due to external causes taking additional time to investigate and complete death certificates. Provisional estimates for most external causes of death (e.g., falls, suicides, unintentional injuries, etc.) are presented with a 6-month lag, while drug overdose deaths are presented with a 9-month lag.
Beginning with the 2018 data year, all 50 states and D.C. reported deaths based on the 2003 revision of the U.S. Standard Certificate of Death for the entire year (1). The revision is based on the 1997 Office of Management and Budget (OMB) standards (1). The 1997 standard allows individuals to report more than one race and increased the race choices from four to five by separating the Asian and Pacific Islander groups. The Hispanic category did not change, remaining consistent with previous reports.

The Hispanic origin and race groups in this report follow the 1997 standards and differ from the race categories used in reports for data years prior to 2018 . From 2003-2017, not all deaths were reported using the 2003 certificate revision that allowed the reporting of more than one race based on the 1997 OMB race standard (1). During those years, multiple-race data were bridged to the 1977 standard single-race categories. Use of the bridged-race process was discontinued for the reporting of mortality statistics in 2018 when all states collected data on race according to 1997 OMB guidelines for the full data year.

\section{Census population data}

The population data used to estimate the life tables shown in this report are April 1, 2020 monthly postcensal population estimates based on the 2010 decennial census and are available from the U.S. Census website at https://www. census.gov/data/tables/time-series/demo/ popest/2010s-national-detail.html.

\section{Preliminary adjustment of the data}

\section{Adjustments for unknown age}

An adjustment is made to account for the small proportion of deaths for which age is not reported on the death certificate. The number of deaths in each age category is adjusted proportionally to account for those with not-stated ages. The following factor $(F)$ is used to make the adjustment. $F$ is calculated for the 
total and for each sex group within a racial and ethnic population for which life tables are constructed:

$$
F=D / D^{a}
$$

where $D$ is the total number of deaths and $D^{a}$ is the total number of deaths for which age is stated. $F$ is then applied by multiplying it by the number of deaths in each age group.

\section{Adjustment for misclassification of Hispanic origin and race on death certificates}

The latest research to evaluate Hispanic origin and race reporting on U.S. death certificates found that the misclassification of Hispanic origin and race on death certificates in the United States accounts for a net underestimate of $3 \%$ for total Hispanic deaths, a net underestimate of less than one-half percent for total non-Hispanic black deaths, and no under or overestimate for total non-Hispanic white deaths (8). These results are based on a comparison of self-reported Hispanic origin and race on Current Population Surveys (CPS) with Hispanic origin and race reported on the death certificates of a sample of decedents in the National Longitudinal Mortality Study (NLMS) who died during the period 1999-2011 (8).

NLMS-linked records are used to estimate sex-age-specific ratios of CPS Hispanic origin and race counts to death certificate counts (9). The CPS/death certificate ratio, or "classification ratio," is specifically the ratio of the weighted count of self-reported race and ethnicity on the CPS to the weighted count of the same racial or ethnic category on the death certificates of the sample of NLMS decedents described above. It can be interpreted as the net difference in assignment of a specific Hispanic origin and race category between the two classification systems and can be used as a correction factor for Hispanic origin and race misclassification (8). The assumption is made that the race and ethnicity reported by a CPS respondent is more reliable than proxy reporting of race and ethnicity by a funeral director who has little personal knowledge of the decedent. Further, public policy embodied in the 1997 OMB standard mandates that self-identification should be the standard used for the collection and recording of race and ethnicity information (8).

The NLMS-based classification ratios discussed above are used to adjust the age-specific number of deaths for ages $1-85$ years and over for the total, Hispanic, non-Hispanic white, and nonHispanic black populations, and by sex for each group, as follows:

$$
{ }_{n} D_{x}={ }_{n} D_{x}^{F} \bullet{ }_{n} C R_{x}
$$

where ${ }_{n} D_{x}^{F}$ is the age-specific number of deaths adjusted for unknown age as described above, ${ }_{n} C R_{x}$ are the sex- and age-specific classification ratios used to correct for the misclassification of Hispanic origin and race on death certificates, and ${ }_{n} D_{x}$ are the final age-specific counts of death adjusted for age and Hispanic origin and race misclassification.

Because NLMS classification ratios for infant deaths are unreliable due to small sample sizes, corrections for racial and ethnic misclassification of infant deaths are addressed by using infant death counts and live birth counts from the linked birth/infant death data files rather than the traditional birth and death data files (1). In the linked file, each infant death record is linked to its corresponding birth record so that the race and ethnicity of the mother reported on the birth record can be ascribed to the infant death record. Due to the unavailability of birth/infant death data at this time, the traditional birth and death data files are used instead for both the 2019 and 2020 life tables. Typically, infant mortality rates based on these data are overestimated by approximately $4 \%$ for the Hispanic population and 3\% for the non-Hispanic black population and underestimated by $2 \%$ for the nonHispanic white population (1).

\section{Calculation of abridged life tables}

Abridged life tables were constructed using the methodology developed by Chiang with minor modifications described below (12). The life table columns include:

\section{Age}

The age interval between two exact ages, $x$ and $x+n$. The abridged life tables contain 19 age groups (in years): $0-1$, $1-5,5-10,10-15, \ldots, 80-85$, and 85 and over.

\section{Probability of dying, ${ }_{n} q_{x}$}

The first step in the calculation of an abridged period life table is the estimation of the age-specific probability of dying, ${ }_{n} q_{x}$. The probability of dying between two exact ages, $x$ and $x+n$, is defined as:

$$
{ }_{n} q_{x}=\frac{n_{x} \bullet{ }_{n} M_{x}}{1+\left(1-a_{x}\right) \bullet n_{x} \bullet{ }_{n} M_{x}}
$$

where ${ }_{n} M_{x}$ is the age-specific period death rate, $\frac{{ }_{n} D_{x}}{{ }_{n} \bullet \frac{1}{2}}$, and ${ }_{n} D_{x}$ is the age-specific provisional death count for January through June, ${ }_{n} P_{x}$ is the April 1 , 2020 age-specific monthly population estimates based on the 2010 decennial population census population count; $n_{x}$ is the size in years of the age interval; and $a_{x}$ is the fraction of life lived by those who died in the age interval.

\section{Number surviving, $l_{x}$}

The number of persons surviving to the beginning of the age interval from the original 100,000 hypothetical live births is defined as:

$$
l_{x+n}=l_{x}-{ }_{n} d_{x}
$$

where the radix of the table $l_{0}=100,000$.

\section{Number dying, ${ }_{n} d_{x}$}

The number of persons dying in the hypothetical life table cohort in the ageinterval $x$ and $x+n$ is defined as:

$$
{ }_{n} d_{x}=l_{x} \bullet{ }_{n} q_{x}
$$




\section{Person-years lived, ${ }_{n} L_{x}$}

The number of person-years lived by the hypothetical life table cohort within an age interval $x$ and $x+n$ is defined as:

$$
{ }_{n} L_{x}=n_{x} \bullet\left(l_{x}-{ }_{n} d_{x}\right)+a_{x} \bullet n_{x} \bullet{ }_{n} d_{x}
$$

where ${ }_{85+} L_{x}$, the person-years lived in the final open-ended age interval, is defined as:

$$
{ }_{s s} L_{x}=\frac{l_{x}}{{ }_{s s} M_{x}}
$$

\section{Total number of person-years lived, $T_{x}$}

The number of person-years that would be lived by the hypothetical life table cohort after the beginning of the age interval $x$ and $x+n$ is defined as:

$$
T_{x}=\sum_{x=0}^{x=85+}{ }_{n} L_{x}
$$

\section{Expectation of life, $\boldsymbol{e}_{\boldsymbol{x}}$}

The average number of years to be lived by those in the hypothetical life table cohort surviving to age $x$ is defined as:

$$
e_{x}=\frac{T_{x}}{l_{x}}
$$

\section{Variances and standard errors of the probability of dying and life expectancy}

Variances are estimated under the assumption that the mortality data on which the life tables are based are not affected by sampling error and subject only to random variation. However, although over $99 \%$ of deaths that occurred from January through June, 2020 are included, the data may be biased by the possibility that certain jurisdictions and age groups may be underrepresented for later months in the period. These errors as well as those resulting from age, Hispanic origin and race misreporting on death certificates are not considered in the calculation of the variances or standard errors of the life table functions.

The methods used to estimate the variances of ${ }_{n} q_{x}$ and $e_{x}$ are based on Chiang (12) with a minor modification in the estimate of the variance of $e_{x}$ in the closing age of the life table (13). Based on the assumption that deaths are binomially distributed, Chiang proposed the following equation for the variance of ${ }_{n} q_{x}$ :

$$
\operatorname{Var}\left({ }_{n} q_{x}\right)=\frac{{ }_{n} q_{x}^{2}\left(1-{ }_{n} q_{x}\right)}{{ }_{n} D_{x}}
$$

where ${ }_{n} D_{x}$ is the age-specific number of deaths, and for the variance of $e_{x}$ for ages under 85:

$$
\operatorname{Var}\left(e_{x}\right)=\frac{\sum_{x=0}^{x=75-84} l_{x}^{2} \bullet\left[\left(1-a_{x}\right) \bullet n_{x}+e_{(x+n)}\right]^{2} \bullet \operatorname{Var}\left({ }_{n} q_{x}\right)}{l_{x}^{2}}
$$

and for ages 85 and over:

$$
\operatorname{Var}\left(e_{85+}\right)=\frac{l_{85+}^{2}}{M_{85+}^{4}} \bullet \operatorname{Var}\left(M_{85+}\right)
$$

\section{Acknowledgments}

The authors are grateful for the content review provided by Sherry L. Murphy, Mortality Statistics Branch (MSB). The authors thank Isabelle Horon, Division of Vital Statistics; Amy B. Branum, Office of the Directory; and Robert N. Anderson, MSB for their reviews and comments. The report was edited and produced by NCHS Office of Information Services, Information Design and Publishing Staff: Yolanda L. Jones and Michael Jones.

\section{Suggested citation}

Arias E, Tejada-Vera B, Ahmad F. Provisional life expectancy estimates for January through June, 2020.

Vital Statistics Rapid Release; no 10. Hyattsville, MD: National Center for Health Statistics. February 2021. DOI: https://dx.doi.org/10.15620/cdc:100392.

\section{Copyright information}

All material appearing in this report is in the public domain and may be reproduced or copied without permission; citation as to source, however, is appreciated.

\section{National Center for Health Statistics}

Brian C. Moyer, Ph.D., Director

Amy M. Branum, Ph.D., Acting Associate Director for Science

\section{Division of Vital Statistics}

Steven Schwartz, Ph.D., Director

Isabelle Horon, Dr.P.H., Acting Associate Director for Science 